\title{
PENERAPAN MODEL PEMBELAJARAN MIND MAPPING DALAM MENINGKATKAN KEMAMPUAN MEMBACA PEMAHAMAN SISWA \\ (Penelitian Tindakan Kelas Pada Siswa Kelas IV Semester 2 SDN Bunisari Kecamatan Jatinunggal Kabupaten Sumedang Tahun Pelajaran 2018/2019)
}

\author{
Awaliyah Dahlani \\ PGSD STKIP Sebelas April Sumedang \\ awaliyah_dahlani@yahoo.com
}

\begin{abstract}
This sudy was motivated by the low ability of students to understand a text, so it needs an alternative in designing an effective model. One model that was considered effective in increasing students' ability to understand a text was the Mind Mapping model. This model was able to help students to remember important information in reading quickly and creatively. This study was focused on efforts to improve students' reading comprehension skills through the application of Mind Mapping model. The purpose of this study was to describe the improvement in students' reading comprehension ability as a result of applying Mind Mapping model. The research method used was classroom action research using Kemmis and Mc.Taggart model. The instrument used were observation paper and test paper. As the subject of this study were students of grade 4 SDN Bunisari consisted of 25 students. Based on the results of data analysis it was known that the application of mind mapping model can improve students' ability to undertstand a text. From the the first (pre test) data, student learning outcomes reached $48 \%$ included in the less category. After the fist cycle, student learning outcomes increased to $76 \%$ included in the good category. After making improvements in the second cycle, student learning outcomes increased to $88 \%$. This shows that the reading comprehension ability of students increases after the implementation of the Mind Mapping model. Therefore the Mind Mapping model can be used as an alternative in learning reading comprehension.
\end{abstract}

Keywords: Mind Mapping Model, Reading Comprehension Skill, Elementary School Students.

\section{ABSTRAK}

Penelitian ini dilatarbelakangi oleh rendahnya kemampuan siswa dalam memahami sebuah bacaan, sehingga perlu adanya alternatif dalam merancang model yang efektif. Salah satu model yang dianggap efektif meningkatkan kemampuan siswa dalam memahami bacaan yaitu model Mind Mapping. Model ini mampu membantu siswa untuk mengingat informasi penting dalam bacaan dengan cepat dan kreatif. Penelitian ini difokuskan kepada upaya meningkatkan kemampuan membaca pemahaman siswa melalui penerapan model Mind Mapping. Tujuan penelitian ini adalah untuk mendapatkan gambaran mengenai peningkatan kemampuan membaca pemahahaman siswa sebagai hasil 
penerapan model Mind Mapping. Metode penelitian yang digunakan adalah penelitian tindakan kelas dengan menggunakan model Kemmis dan Mc. Taggart. Instrumen yang digunakan berupa lembar observasi dan lembar tes. Subjek dalam penelitian ini adalah siswa kelas IV SDN Bunisari yang berjumlah 25 orang. Berdasarkan hasil analisis data diketahui bahwa penerapan model Mind Mapping dapat meningkatkan kemampuan siswa dalam memahami bacaan. Dari data awal ketuntasan hasil belajar siswa mencapai $48 \%$ dalam kategori kurang. Setelah dilakukan siklus I, meningkat menjadi $76 \%$ dalam kategori baik. Setelah dilakukan perbaikan pada siklus II ketuntasan hasil belajar siswa meningkat menjadi $88 \%$. Hal ini menunjukkan bahwa kemampuan membaca pemahaman siswa meningkat setelah diterapkannya model Mind Mapping. Oleh karena itu, model Mind Mapping dapat digunakan sebagai alternatif dalam pembelajaran membaca pemahaman.

Kata kunci: Model Pembelajaran Mind Mapping, Kemampuan Membaca Pemahaman, Siswa Sekolah Dasar.

\section{A. Pendahuluan}

Membaca

merupakan

keterampilan berbahasa yang mendasar dalam kehidupan setiap manusia. Manusia dalam setiap aspek kehidupannya, memerlukan kegiatan membaca untuk memperoleh berbagai informasi yang dibutuhkan dalam menjalani kehidupannya sehari-hari. Oleh karena itu, keterampilan membaca merupakan hal penting yang harus dikuasai oleh manusia. Hal ini sejalan dengan pendapat Tarigan (2008:iii) yang menyatakan bahwa kemampuan baca para siswa dan mahasiswa turut menentukan taraf kemajuan masa depan bangsa dan negara. Sejalan dengan Tarigan, Burns, dkk (Rahim, 2011, hlm. 1) mengemukakan bahwa kemampuan membaca merupakan sesuatu yang vital dalam suatu masyarakat terpelajar. Hal ini menunjukkan bahwa kemampuan membaca dibutuhkan oleh setiap manusia untuk memperoleh informasi-informasi penting sebagai sarana untuk mendapatkan kehidupan yang lebih baik lagi.

$$
\text { Membaca bukan hanya }
$$
melafalkan lambang-lambang tulisan saja, tapi lebih dari itu pembaca harus mampu memahami berbagai informasi yang terkandung dalam teks yang dibacanya. Jadi sesungguhnya esensi dari membaca adalah pemahaman. Oleh karena itu pembelajaran membaca pemahaman perlu diajarkan secara serius di sekolah dasar dengan menggunakan model yang tepat.

Mengenai pembelajaran membaca di sekolah dasar, ada 
Pendas : Jurnal IImiah Pendidikan Dasar, ISSN Cetak : 2477-2143 ISSN Online : 2548-6950 Volume IV Nomor 2, Desember 2019

beberapa hal yang harus diperhatikan, diantaranya yaitu pembelajaran membaca harus diarahkan kepada ketercapaian tujuan membaca. Menurut Abidin (2012, hlm. 5) minimalnya ada tiga tujuan utama pembelajaran membaca di sekolah, yaitu: 1) memungkinkan siswa agar mampu menikmati kegiatan membaca; 2) mampu membaca dalam hati dengan kecepatan baca yang fleksibel; dan 3) memperoleh tingkat pemahaman yang cukup atas isi bacaan. Berdasarkan pernyataan tersebut, jelas bahwa salah satu tujuan pembelajaran membaca di sekolah adalah pemerolehan pemahaman atas isi bacaan, bukan hanya semata-mata agar siswa mampu membaca saja.

Mengingat pentingnya peran membaca pemahaman dalam kegiatan pembelajaran di sekolah dasar, maka membaca pemahaman merupakan keterampilan yang penting untuk dimiliki oleh siswa sekolah dasar. Namun pada kenyataannya, kemampuan membaca pemahaman siswa sekolah dasar masih rendah. Hal ini bisa dilihat dari observasi awal di kelas IV SDN Bunisari

Kecamatan
Jatinunggal. Dari hasil observasi tersebut diketahui bahwa kemampuan membaca pemahaman siswa kelas IV SDN Bunisari yang berjumlah 25 orang masih rendah. Siswa yang memperoleh nilai kurang dari 70 sebanyak 13 siswa atau 52\%, sedangkan yang memperoleh nilai lebih dari 70 sebanyak 12 siswa atau $48 \%$. Padahal kriteria yang diharapkan adalah $85 \%$ siswa memperoleh nilai di atas $\mathrm{KKM}$, yaitu 70.

Jika melihat permasalahan yang terjadi, diduga yang menjadi penyebabnya salah satunya adalah penggunaan model pembelajaran yang kurang efektif. Model pembelajaran adalah prosedur atau pola sistematis yang digunakan sebagai pedoman untuk mencapai tujuan pembelajaran yang diharapkan. Model pembelajaran yang efektif dapat membantu meningkatkan aktivitas dan hasil belajar siswa. Salah satu model pembelajaran yang efektif dalam upaya pemahaman bacaan adalah model Mind Mapping. Menurut Shoimin (2014:105) "Model pembelajaran Mind Mapping adalah model pembelajaran yang meminta peserta didik untuk membuat Mind 
Mapping (peta pikiran), sehingga memungkinkan peserta didik mengidentifikasi dengan jelas dan kreatif apa yang telah dipelajari atau apa yang tengah direncanakan."

Nugraha (2016:8) menyatakan bahwa "Menggunakan model Mind Mapping bisa menstimulus peserta didik untuk berani aktif dalam kegiatan pembelajaran. Keberhasilan proses pembelajaran tak lepas dari keterampilan pendidik bagaimana mengelola proses pembelajarannya, misalnya menggunakan model pembelajaran Mind Mapping sehingga dapat meningkatkan aktivitas dan hasil belajar siswa".

Model pembelajaran Mind Mapping merupakan model yang dirancang untuk membantu siswa dalam proses memahami bacaan, menyimpan informasi, dan membantu siswa menyusun inti-inti yang penting dari sebuah bacaan. Melalui model pembelajaran Mind Mapping, siswa akan mengetahui topik utama bacaan, menentukan kalimat utama, kemudian membuat peta pikirannya masing-masing sesuai dengan kreativitas mereka.

Mengenai penggunaan model Mind Mapping, sudah ada beberapa penelitian terdahulu. Penelitian tersebut diantaranya dilakukan oleh Mudalifa tahun 2018 yang berjudul, "Pengaruh model pembelajaran mind mapping terhadap hasil belajar tema 2 subtema 1 peserta didik kelas IV SDN 2 Tanjung Senang" berdasarkan hasil penelitian yang dilakukan terdapat peningkatan antara pretest dan posttest hasil belajar siswa dengan menggunakan model pembelajaran mind mapping, dapat diakui bahwa model pembelajaran mind mapping dapat meningkatkan hasil belajar siswa.

\section{B. Metode Penelitian}

Metode yang digunakan dalam penelitian ini adalah Penelitian Tindakan Kelas (PTK). Ebbut (Wiriaatmadja, 2009:12) mengemukakan bahwa penelitian tindakan adalah kajian sistematik dari upaya perbaikan pelaksanaan praktek pendidikan oleh sekelompok guru dengan melakukan tindakantindakan dalam pembelajaran, berdasarkan refleksi mereka mengenai hasil dari tindakantindakan tersebut. Mc. Niff (Sukidin, dkk., 2010:14) memandang PTK sebagai bentuk penelitian reflektif yang dilakukan oleh guru sendiri yang hasilnya dapat dimanfaatkan sebagai 
alat untuk pengembangan kurikulum, pengembangan sekolah, pengembangan keahlian mengajar, dan sebagainya.

Model penelitian yang digunakan dalam penelitian ini adalah model siklus Kemmis dan Taggart yang terdiri dari empat komponen yaitu perencanaan, tindakan, observasi, dan refleksi. Model spiral dari Kemmis dan Taggart (Wiriaatmadja, 2009: 66) dapat dilihat pada gambar di bawah ini.

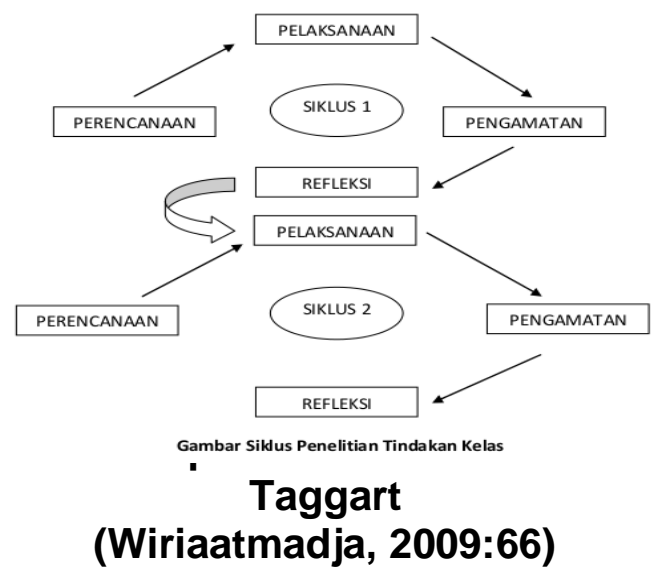

Penelitian ini dilaksanakan dengan prosedur berupa siklus, banyaknya siklus bergantung pada pencapaian target penelitian, dan jika target penelitian sudah tercapai maka siklus pun dihentikan. Setiap siklus dilakukan dalam satu pertemuan. Penelitian ini akan melaksanakan empat langkah prosedur penelitian sebagai berikut:
1. Perencanaan (Plan)

Langkah-langkah perencanaan tindakan yang dilakukan adalah sebagai berikut:

a. Permohonan izin kepada kepala sekolah.

b. Mengadakan penelitian awal untuk memperoleh data melalui pre test.

c. Memperkenalkan model pembelajaran Mind Mapping yang dianggap efektif untuk pencapaian tujuan pembelajaran.

d. Menyusun RPP dengan menerapkan model pembelajaran Mind Mapping.

e. Menyiapkan lembar observasi dan tes hasil belajar.

2. Tindakan (Action)

Pada tahap tindakan ini, peneliti melaksanakan proses pembelajaran dengan menggunakan model Mind Mapping sesuai dengan Rencana Pelaksanaan Pembelajaran (RPP) yang telah dirancang sebelumnya.

3. Pengamatan (Observe)

Pengamatan

dilakukan bersamaan dengan proses pelaksanaan tindakan. Dalam penelitian ini, observasi dilaksanakan selama proses pembelajaran membaca pemahaman dengan menggunakan alat pengumpul data yang sudah ditetapkan. Alat 
pengumpul data yang ditetapkan yaitu lembar tes dan lembar observasi dengan fokus yang diobservasi yaitu siswa kelas IV SDN Bunisari. Hasil observasi yang diperoleh pada tahap selanjutnya dijadikan bahan kajian peneliti untuk mengukur keberhasilan penelitian.

\section{Refleksi (Reflect)}

Refleksi merupakan kegiatan pengkajian data yang dihasilkan dari kegiatan observasi dan tes untuk memaknai perubahan yang terjadi selama pembelajaran. Sebagaimana pendapat dari Karwati dan Priansa (2015: 309) yang mengungkapkan "Refleksi merupakan kegiatan analisis, sintesis, interpretasi, terhadap semua informasi yang diperoleh saat kegiatan tindakan". Dalam pelaksanaan tindakan dilakukan evaluasi terhadap keberhasilan dan pencapaian tujuan tindakan. Setelah mendapatkan hasil dari keseluruhan tindakan, maka peneliti memperbaiki proses pembelajaran yang telah dilakukan secara berkelanjutan sampai pada target yang dihendaki.

Penelitian ini berlokasi di SDN Bunisari Kecamatan Jatinunggal Kabupaten Sumedang. Populasi yang digunakan yaitu siswa kelas IV di
SDN Bunisari yang berjumlah 25 orang. Populasi tersebut langsung dijadikan sampel. Teknik ini disebut teknik sampling jenuh.

Untuk memperoleh data yang diperlukan, peneliti menyusun dan menyiapkan instrumen untuk menjawab pertanyaan penelitian, yaitu instrumen tes membaca pemahaman dan observasi. Wacana yang digunakan dalam penelitian ini adalah wacana berjenis ekspositori, karena kesesuaiannya dengan model yang diteliti. Tes membaca pemahaman digunakan untuk mengukur kemampuan siswa dalam memahami bacaan. Tes ini berupa soal pilihan ganda sebanyak 20 buah, setiap nomor diberi skor 5 sehingga diperoleh skor maksimal 100.

\section{C.Hasil Penelitian dan \\ Pembahasan}

Sebelum pelaksanaan tindakan, terlebih dahulu siswa diberi pre test sebagai upaya untuk mengetahui kemampuan awal siswa. Kemampuan awal siswa sebelum dilaksanakan tindakan dapat dilihat pada tabel berikut ini. 
Tabel 1

Data Awal Hasil Tes Siswa

\begin{tabular}{|c|c|c|c|c|}
\hline \multirow[t]{2}{*}{ No. } & \multirow[t]{2}{*}{ Nama } & \multirow[t]{2}{*}{ Nilai } & \multicolumn{2}{|c|}{ Keterangan } \\
\hline & & & Tuntas & $\begin{array}{l}\text { Belum } \\
\text { Tuntas }\end{array}$ \\
\hline 1 & $\mathrm{~S} 1$ & 65 & & $\sqrt{ }$ \\
\hline 2 & S2 & 75 & $\sqrt{ }$ & \\
\hline 3 & S3 & 70 & $\sqrt{ }$ & \\
\hline 4 & S4 & 80 & $\sqrt{ }$ & \\
\hline 5 & S5 & 65 & & $\sqrt{ }$ \\
\hline 6 & S6 & 75 & $\sqrt{ }$ & \\
\hline 7 & S7 & 65 & & $\sqrt{ }$ \\
\hline 8 & S8 & 70 & $\sqrt{ }$ & \\
\hline 9 & S9 & 85 & $\sqrt{ }$ & \\
\hline 10 & $\mathrm{~S} 10$ & 70 & $\sqrt{ }$ & \\
\hline 11 & S11 & 55 & & $\sqrt{ }$ \\
\hline 12 & S12 & 75 & $\sqrt{ }$ & \\
\hline 13 & $\mathrm{~S} 13$ & 70 & $\sqrt{ }$ & \\
\hline 14 & S14 & 45 & & $\sqrt{ }$ \\
\hline 15 & S15 & 50 & & $\sqrt{ }$ \\
\hline 16 & S16 & 45 & & $\sqrt{ }$ \\
\hline 17 & S17 & 70 & $\sqrt{ }$ & \\
\hline 18 & S18 & 70 & $\sqrt{ }$ & \\
\hline 19 & S19 & 75 & $\sqrt{ }$ & \\
\hline 20 & S20 & 55 & & $\sqrt{ }$ \\
\hline 21 & S21 & 60 & & $\sqrt{ }$ \\
\hline 22 & S22 & 50 & & $\sqrt{ }$ \\
\hline 23 & S23 & 50 & & $\sqrt{ }$ \\
\hline 24 & S24 & 55 & & $\sqrt{ }$ \\
\hline 25 & S25 & 50 & & $\sqrt{ }$ \\
\hline Jum & & 1440 & 12 & 13 \\
\hline Rata & ata & 57,6 & & \\
\hline Pers & ntase & & $48 \%$ & $52 \%$ \\
\hline
\end{tabular}

diketahui 13 siswa mendapatkan nilai kurang dari 70, sedangkan 12 siswa telah mendapatkan nilai lebih dari 70, hal ini berarti hanya 48\% siswa yang dinyatakan tuntas sedangkan 58\% siswa lainnya masih belum tuntas. Satu kelas dikatakan telah berhasil atau mencapai ketuntasan belajar jika paling sedikit $85 \%$ dari jumlah siswa dalam satu kelas tersebut telah tercapai keberhasilan belajar. Berdasarkan data awal tersebut, dilaksanakan pembelajaran menggunakan model pembelajaran mind mapping yang dimulai dengan siklus I.

\section{Tahap Pelaksanaan Siklus I}

Pelaksanaan tindakan siklus I dilaksanakan selama satu kali pertemuan. Pelaksanaan tindakan di dalam kelas sesuai dengan Rencana Pelaksanaan Pembelajaran (RPP). Adapun proses pembelajaran dilaksanakan dalam tiga tahap pembelajaran, yaitu kegiatan awal, kegiatan inti dan kegiatan akhir.

\section{a. Kegiatan Awal}

Kegiatan awal pembelajaran dimulai dengan berdoa bersama yang dipandu oleh salah satu siswa. Setelah itu guru menyampaikan tujuan pembelajaran dan juga memberitahu materi yang akan dipelajari.

b. Kegiatan Inti

Pada kegiatan inti, guru membagikan bahan bacaan kepada setiap siswa. Kemudian guru meminta siswa untuk mencatat poinpoin penting informasi yang ada dalam bacaan. Guru membagi siswa kedalam 4 kelompok (tiap kelompok terdiri dari 6-7 orang siswa). Setelah 
selesai membagi kelompok guru memberikan kertas HVS berwarna untuk dibuat peta pikiran sesuai dengan poin- poin penting dari bacaan yang telah ditulis oleh siswa dengan menggunakan spidol warna yang telah di siapkan. Guru membimbing siswa dalam mengerjakan lembar kerja siswa tersebut. Setelah semua kelompok selesai membuat peta pikiran (mind mapping) kemudian siswa diminta untuk mempresentasikan hasil diskusinya. Guru melakukan tanya jawab dengan siswa tentang materi yang telah disampaikan. Guru dan siswa menyimpulkan pembelajaran.

c. Kegiatan Akhir

Kegiatan pembelajaran diakhiri dengan memberikan soal tes formatif membaca pemahaman. Setelah selesai mengerjakan soal, guru menginstruksikan ketua kelas untuk berdoa dan mengakhiri pembelajaran.

\section{Hasil Belajar Membaca Pemahaman Siklus I}

Hasil belajar membaca pemahaman yang diperoleh dari hasil tes formatif pada siklus I adalah sebagai berikut.
Tabel 2

Data Hasil Belajar Siswa Siklus I

\begin{tabular}{|c|c|c|c|c|c|}
\hline \multirow[b]{2}{*}{ No } & \multirow[b]{2}{*}{$\begin{array}{c}\text { Nam } \\
\text { a }\end{array}$} & \multirow[b]{2}{*}{ Skor } & \multirow[b]{2}{*}{ Nilai } & \multicolumn{2}{|c|}{ Keterangan } \\
\hline & & & & Tuntas & $\begin{array}{l}\text { Belum } \\
\text { Tunta } \\
\text { s }\end{array}$ \\
\hline 1 & S1 & 15 & 75 & $\sqrt{ }$ & \\
\hline 2 & S2 & 17 & 85 & $\sqrt{ }$ & \\
\hline 3 & S3 & 15 & 75 & $\sqrt{ }$ & \\
\hline 4 & S4 & 20 & 100 & $\sqrt{ }$ & \\
\hline 5 & S5 & 15 & 75 & $\sqrt{ }$ & \\
\hline 6 & S6 & 18 & 90 & $\sqrt{ }$ & \\
\hline 7 & S7 & 15 & 75 & $\sqrt{ }$ & \\
\hline 8 & S8 & 15 & 75 & $\sqrt{ }$ & \\
\hline 9 & S9 & 20 & 100 & $\sqrt{ }$ & \\
\hline 10 & $\mathrm{~S} 10$ & 17 & 85 & $\sqrt{ }$ & \\
\hline 11 & S11 & 14 & 70 & $\sqrt{ }$ & \\
\hline 12 & S12 & 19 & 95 & $\sqrt{ }$ & \\
\hline 13 & $\mathrm{~S} 13$ & 15 & 75 & $\sqrt{ }$ & \\
\hline 14 & S14 & 13 & 65 & & $\sqrt{ }$ \\
\hline 15 & S15 & 13 & 65 & & $\sqrt{ }$ \\
\hline 16 & S16 & 13 & 65 & & $\sqrt{ }$ \\
\hline 17 & S17 & 15 & 75 & $\sqrt{ }$ & \\
\hline 18 & S18 & 15 & 75 & $\sqrt{ }$ & \\
\hline 19 & S19 & 18 & 90 & $\sqrt{ }$ & \\
\hline 20 & S20 & 15 & 75 & $\sqrt{ }$ & \\
\hline 21 & S21 & 14 & 70 & $\sqrt{ }$ & \\
\hline 22 & S22 & 13 & 65 & & $\sqrt{ }$ \\
\hline 23 & S23 & 13 & 65 & & $\sqrt{ }$ \\
\hline 24 & S24 & 14 & 70 & $\sqrt{ }$ & \\
\hline 25 & S25 & 13 & 65 & & $\sqrt{ }$ \\
\hline & Juml & & 1920 & 19 & 6 \\
\hline & Rata-r & & 76.8 & & \\
\hline & rsenta & (\%) & & $76 \%$ & $24 \%$ \\
\hline
\end{tabular}

\section{Kegiatan Refleksi di Siklus I}

Setelah kegiatan pembelajaran di siklus I selesai, kemudian dilakukan refleksi bersama dengan guru kelas IV SDN Bunisari sebagai lokasi penelitian. Kegiatan ini dilakukan untuk memperbaiki permasalahan yang terjadi pada siklus I agar tidak ditemukan lagi pada siklus II sehingga hasil belajar siswa 
Pendas : Jurnal IImiah Pendidikan Dasar, ISSN Cetak : 2477-2143 ISSN Online : 2548-6950

Volume IV Nomor 2, Desember 2019

diharapkan bisa meningkat. Dari hasil refleksi diketahui bahwa hasil tes formatif di siklus I ada 6 orang siswa yang termasuk dalam kategori belum tuntas. Setelah diperhatikan, ternyata siswa tersebut rata-rata berada pada kelompok yang sama saat pembelajaran. Pada kegiatan inti, guru memberikan wewenang kepada siswa untuk memilih sendiri rekan kelompoknya. Siswa yang pintar cenderung memilih siswa yang pintar lagi untuk menjadi anggota kelompoknya, begitu juga siswa yang kurang pintar, sehingga kelompok yang terbentuk bersifat homogen. Oleh karena itu, pada siklus II guru sebaiknya mengelompokkan siswa dengan komposisi yang heterogen.

\section{Hasil Belajar Membaca \\ Pemahaman Siklus II}

Hasil belajar membaca pemahaman yang diperoleh dari hasil tes formatif pada siklus II adalah sebagai berikut:

Tabel 2

Data Hasil Belajar Siswa Siklus II

\begin{tabular}{|llcccc|}
\hline \multirow{2}{*}{ No } & Nama & Skor & Nilai & \multicolumn{2}{c|}{ Keterangan } \\
\cline { 5 - 6 } & & & & & $\begin{array}{c}\text { Tuntas } \\
\text { Tuntas }\end{array}$ \\
\hline 1 & S1 & 18 & 90 & $\sqrt{ }$ & \\
\hline 2 & S2 & 18 & 90 & $\sqrt{ }$ & \\
\hline 3 & S3 & 18 & 90 & $\sqrt{ }$ \\
\hline 4 & S4 & 20 & 100 & $\sqrt{ }$ \\
\hline 5 & S5 & 14 & 70 & $\sqrt{ }$ \\
\hline
\end{tabular}

\begin{tabular}{|c|c|c|c|c|c|}
\hline 6 & S6 & 20 & 100 & $\sqrt{ }$ & \\
\hline 7 & S7 & 17 & 85 & $\sqrt{ }$ & \\
\hline 8 & S8 & 18 & 90 & $\sqrt{ }$ & \\
\hline 9 & S9 & 20 & 100 & $\sqrt{ }$ & \\
\hline 10 & S10 & 20 & 100 & $\sqrt{ }$ & \\
\hline 11 & $\mathrm{~S} 11$ & 17 & 85 & $\sqrt{ }$ & \\
\hline 12 & $\mathrm{~S} 12$ & 20 & 100 & $\sqrt{ }$ & \\
\hline 13 & $\mathrm{~S} 13$ & 18 & 90 & $\sqrt{ }$ & \\
\hline 14 & S14 & 14 & 70 & $\sqrt{ }$ & \\
\hline 15 & S15 & 13 & 65 & & $\sqrt{ }$ \\
\hline 16 & S16 & 18 & 90 & $\sqrt{ }$ & \\
\hline 17 & S17 & 18 & 90 & $\sqrt{ }$ & \\
\hline 18 & S18 & 19 & 95 & $\sqrt{ }$ & \\
\hline 19 & S19 & 20 & 100 & $\sqrt{ }$ & \\
\hline 20 & S20 & 18 & 90 & $\sqrt{ }$ & \\
\hline 21 & S21 & 16 & 80 & $\sqrt{ }$ & \\
\hline 22 & S22 & 13 & 65 & & $\sqrt{ }$ \\
\hline 23 & S23 & 12 & 60 & & $\sqrt{ }$ \\
\hline 24 & S24 & 14 & 70 & $\sqrt{ }$ & \\
\hline 25 & S25 & 16 & 80 & $\sqrt{ }$ & \\
\hline \multicolumn{2}{|c|}{ Jumlah } & & 2145 & 22 & 3 \\
\hline \multicolumn{2}{|c|}{ Rata-rata } & & 85.8 & & \\
\hline \multicolumn{2}{|c|}{$\begin{array}{c}\text { Persentase } \\
(\%)\end{array}$} & & & $38 \%$ & $12 \%$ \\
\hline
\end{tabular}

Dari tabel di atas diketahui bahwa siswa yang belum tuntas menurun dari 6 orang siswa di siklus I menjadi 3 orang di siklus II. Hal ini menunjukkan bahwa ada peningkatan kemampuan siswa dalam memahami bacaan dengan menggunakan model Mind Mapping.

\section{Data Peningkatan Kemampuan} Membaca Pemahaman Siswa

Peningkatan kemampuan membaca pemahaman siswa dapat dilihat dari skor rata-rata kelas pada setiap siklusnya. Data peningkatan tersebut dapat dilihat pada grafik di bawah ini. 


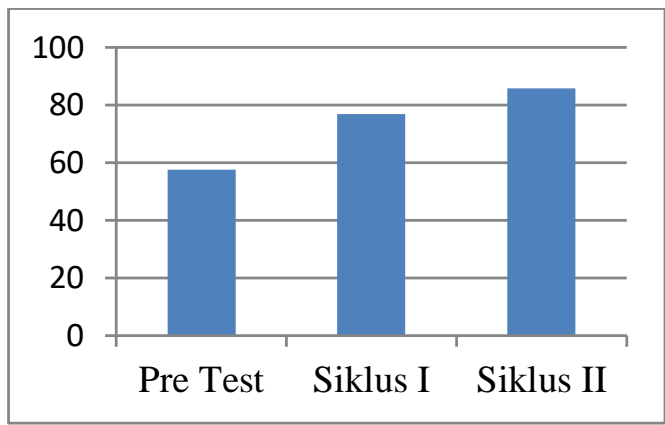

Grafik 1

Peningkatan Kemampuan Membaca Pemahaman Siswa

Berdasarkan hasil analisis dan refleksi pembelajaran siklus II, dapat disimpulkan bahwa pembelajaran siklus II dengan menggunakan model pembelajaran Mind Mapping sudah terlaksana secara optimal. Hal ini bisa terlihat dari penghitungan ratarata kenaikan kemampuan membaca pemahaman siswa dari kemampuan awal (pre test) ke siklus II adalah $22 \%$. Begitu juga dengan persentase ketuntasan belajar siswa meningkat dari $76 \%$ menjadi $88 \%$ dan dinyatakan cukup. Penerapan model pembelajaran Mind Mapping terbukti dapat meningkatkan kemampuan membaca pemahaman siswa. Oleh karena itu, tidak perlu lagi dilakukan upaya perbaikan pada siklus selanjutnya karena persentase sudah mencapai target, dengan demikian penelitian diakhiri.

\section{E. Kesimpulan}

Penerapan model pembelajaran mind mapping dapat meningkatkan kemampuan membaca pemahaman siswa. Hal ini dilihat dari nilai hasil data awal (pre test), nilai akhir siklus I, dan nilai akhir siklus II yang menunjukkan terjadinya peningkatan siswa yang tuntas dan memenuhi KKM. Pada data awal terdapat 12 siswa yang tuntas atau sebesar $48 \%$ dan terdapat 13 siswa yang tidak tuntas atau sebesar 52\% dengan rata-rata nilai siswa sebesar 57,6 (cukup). Pada perbaikan siklus I persentase hasil belajar siswa yang tuntas sebanyak 19 orang atau sebesar $76 \%$. Dari data awal ke siklus I mengalami peningkatan sebesar $28 \%$, dan siswa yang tidak tuntas di siklus I sebanyak 6 orang atau sebanyak $24 \%$ dengan rata- rata nilai siswa sebesar 76,8 (baik). Walaupun ada peningkatan dari kondisi awal ke siklus I, tetapi masih belum mencapai target yang ditentukan. Pembelajaran membaca pemahaman dengan menerapkan model pembelajaran mind mapping pada siklus II mendapatkan hasil yang lebih baik dari kondisi awal dan siklus I. Pada siklus II terdapat 22 orang atau sebesar $88 \%$ yang tuntas 
belajar dan mengalami peningkatan dari siklus I sebesar 12\% dengan rata-rata nilai siswa sebesar 85,8 (baik). Rata- rata peningkatan hasil belajar dari data awal ke siklus II sebesar $22 \%$ yang tergolong pada kategori kurang. Dengan melihat pemaparan di atas penulis dapat menyimpulkan bahwa peningkatan kemampuan membaca pemahaman siswa telah cukup optimal. Penerapan model pembelajaran Mind Mapping terbukti dapat meningkatkan kemampuan membaca pemahaman siswa.

\section{DAFTAR PUSTAKA}

Abidin, Y. (2012). Pembelajaran Membaca Berbasis Karakter. Bandung : Refika Aditama.

Karwati, E. \& Priansa, D. J. (2014). Manajemen Kelas Guru Profesional yang Inspiratif, Kreatif, Menyenangkan dan Berprestasi. Bandung: Alfabeta.

Nugraha. (2016). Perkembangan Media Informasi dan Teknologi Terhadap anak dalam Era Global. In: Prosiding the 5th international conference on Indonesian studies: Ethnicity dan Globalitation.

Rahim, F. (2011). Pengajaran Membaca di Sekolah Dasar. Jakarta : Bumi Aksara.

Shoimin, A. (2014). Model Pembelajaran Inovatif dalam Kurikulum 2013. Jakarta: Ar-Ruzz Media.
Sukidin, dkk. (2010). Manajemen Penelitian Tindakan Kelas. Surabaya : Insan Cendekia.

Targian, H. G. (2008). Membaca sebagai Suatu Keterampilan Berbahasa (Edisi Revisi). Bandung : Angkasa.

Wiriaatmadja, R. (2009). Metode Penelitian Tindakan Kelas. Bandung : PT Remaja Rosdakarya. 